ARTIGOS - ARTICLES

\title{
Para una historia conceptual de lo social
}

\author{
Carlos Illades \\ División de Ciencias Sociales y Humanidades \\ Universidad Autónoma Metropolitana \\ cillades@correo.cua.uam.mx
}

Como citar este artigo: Illades, Carlos. "Para una historia conceptual de lo social". Intelligere, Revista de História Intelectual, vol. 1, nº1, p. 16-25. 2015. Disponível em <http://revistas.usp.br/revistaintelligere>. Acesso em $\mathrm{dd} / \mathrm{mm} /$ aaaa.

Resumo: até agora, a história conceitual tem tomado como objeto de estudo fundamental a linguagem política, deixando de lado o conjunto de significados referentes ao social. Podemos considerar isso como uma consequência da hegemonia do pensamento liberal dentro do discurso público e das repercussões do que ele produziu dentro do campo historiográfico. Ainda que pouco se tenha trabalhado nele, tanto o materialismo cultural - Raymond Williams, Richard Hoggart e E. P. Thompson - como "a história vista de baixo" - Thompson, Eric Hobsbawm, George Rudé, Christopher Hill e Rodney Hilton - oferecem um corpus o suficientemente vasto para recuperar a história conceitual do social.

Palavras-chave: história intelectual - história conceitual - linguagem política - materialismo cultural - história conceitual do social.

\section{For a conceptual history of the social}

\begin{abstract}
: until now, the conceptual history has taken as fundamental subject matter the political language, leaving aside the set of meanings for the social. We can consider this as a result of the hegemony of liberal thought within the public discourse and the repercussions of what he produced in the historiographical field. Although little has worked on it, both cultural materialism - Raymond Williams, Richard Hoggart and EP Thompson - and "history from below" - Thompson, Eric Hobsbawm, George Rudé Christopher Hill and Rodney Hilton - They provide a sufficiently large corpus to recover the concept of social history.
\end{abstract}

Keywords: Intellectual History - conceptual history - political language cultural materialism - conceptual history of social. 
Hasta ahora, la historia conceptual ha tomado como objeto de estudio fundamental el lenguaje político, dejando de lado el conjunto de significados referidos a lo social. Esto podemos considerarlo una consecuencia de la hegemonía del pensamiento liberal dentro del discurso público y de las repercusiones que ello produjo dentro del campo historiográfico. Los importantes trabajos de Pierre Rosanvallon, sobre Francia, y los de Elías José Palti, acerca de América Latina, en parte influidos por el discípulo de François Furet, constituyen ejemplos relevantes de esta tendencia, ${ }^{1}$ si bien en los últimos años Rosanvallon se ocupó en la formulación de la "nueva cuestión social", esto es, la tensión entre democracia y desigualdad en las sociedades contemporáneas.

Aunque poco se ha trabajado en ello, tanto el materialismo cultural -Raymond Williams, Richard Hoggart y E.P. Thompson -, y la "historia desde abajo" - Thompson, Eric Hobsbawm, George Rudé, Cristopher Hill y Rodney Hilton -, ofrecen un corpus lo suficientemente vasto para recuperar la historia conceptual de lo social. Debemos a Williams el mejor registro de ésta a partir de la Revolución industrial. Culture and society (1958) expuso cómo adquirieron relevancia las palabras industria, clase, cultura, democracia y arte cuando la maquinización alteró de forma definitiva la reproducción social. O, para emplear las propias categorías del pensador galés, el proceso mediante el cual la revolución dentro de la esfera productiva generó una "estructura de sentimiento" particular donde estos conceptos cobraban sentido dentro de un lenguaje común que rebasaba las fronteras ideológicas y temporales, situando en un mismo horizonte a escritores diversos. ${ }^{2}$ Keywords (1978) extendió el análisis a varias decenas de palabras que constituyen el vocabulario básico de la cultura y la sociedad:

de las alrededor de doscientas palabras que escogí por haberlas leído o escuchado en discusiones muy generales con usos que me parecían interesantes o difíciles, seleccioné luego sesenta y escribí un apéndice de Culture and Society, que en su texto principal se refería a una serie de escritores y pensadores. Pero cuando terminé ese libro, mi editor me dijo que había que acortarlo: una de las cosas que podían eliminarse era ese apéndice... Durante más de veinte años le hecho agregados: reuní ejemplos, encontré nuevos puntos de análisis, incorporé otras nuevas palabras. ${ }^{3}$

Culture and Society no fue de fácil asimilación por parte de sus contemporáneos, comenzando por la dificultad de adscribirlo a una disciplina en particular. Lo que para algunos era historia cultural, para otros era "semántica histórica, historia de las ideas, crítica social, historia literaria y sociología”. Es decir, el variado abanico que conformaría a partir de los ochenta, gracias a los pioneros estudios de Williams, el campo de los Estudios culturales; también lo podemos llamar convencionalmente "interdisciplina". De esto fue plenamente consciente el historiador galés cuando publicó Keywords: "el trabajo que registra este libro en un

\footnotetext{
${ }^{1}$ Pierre Rosanvallon, "La consagración del ciudadano" en Historia del sufragio universal en Francia (México: Instituto Mora, 1999); Pierre Rosanvallon, Por una bistoria conceptual de lo político (Buenos Aires: FCE, 2002); Pierre Rosanvallon, "El pueblo inalcanzable" en Historia de la representación democrática en Francia (México: Instituto Mora, 2004); Elías José Palti, "La nación como problema" en Los historiadores y la "cuestión nacional" (Buenos Aires: FCE, 2002); Elías José Palti, "El tiempo de la política" en El siglo XIX reconsiderado (Buenos Aires: Siglo Veintiuno, 2007). Sobre la perspectiva de Rosanvallon puede verse François Dosse, "La marcha de las ideas" em Historia de los intelectuales, historia intelectual (Valencia: PUV, 2007), 243-249.

${ }^{2}$ Raymond Williams, Cultura y sociedad. De Coleridge a Orvell (Buenos Aires: Nueva Visión, 2001); Maria Elisa Cevasco, Para leer a Raymond Williams (Buenos Aires: Universidad Nacional de Quilmes, 2003), 161. ${ }^{3}$ Raymond Williams, Palabras clave. Un vocabulario de la cultura y la sociedad (Buenos Aires: Claves, 2000), 1819.
} 
área donde diversas disciplinas convergen pero en general no se encuentran". ${ }^{4}$ De ese feliz "desencuentro", sin embargo, surgió una fructífera problematización acerca del estudio histórico de los conceptos, de la relación indisoluble con sus referentes sociales, el lenguaje corriente que los nombra y de su entrelazamiento en sistemas de pensamiento complejos e ideologías, cuestiones que abordaremos en las siguientes páginas.

\section{ALGUNOS PROBLEMAS}

Sin proponer un método, Williams dejó algunos trazos sobre cómo reunir "un vocabulario de la cultura y la sociedad"; otros más podemos entresacarlos de sus escritos. Antes de que se pusiera de moda el "giro lingüístico" entre los historiadores, el pensador galés reivindicó la centralidad del lenguaje en la constitución del mundo social apuntando que aquél no es un simple vehículo de la comunicación, pues es constituyente de la realidad y posee tanto una materialidad práctica como una historicidad específica, ambas eminentemente colectivas. Únicamente "vemos" la realidad cuando empleamos esquemas perceptivos construidos socialmente, y situados temporal y espacialmente. Asimismo, como comprobó Williams en sus investigaciones, que "sobre muchas de las cuestiones no podía reflexionarse exhaustivamente, y algunas de ellas, creo, no pueden ni siquiera abordase al menos de que seamos conscientes de las palabras como elementos de los problemas”. En esta dirección, Stedman Jones señaló que "el lenguaje desecha cualquier simple concepto de determinación de la concienciación por el ser social porque él mismo es parte del ser social". 5

El lenguaje verbaliza la experiencia y ésta adquiere un significado dentro de la "estructura de sentimiento" dominante en cada época, un todo orgánico pautado a su vez por los grupos sociales más poderosos. Planteamiento semejante a la tesis gramsciana sobre la "hegemonía cultural" de las clases dominantes, las cuales se transforman en dirigentes justamente cuando imponen su concepción del mundo, esto es una ideología, al conjunto de la sociedad. ${ }^{6}$ Emparentado también al materialismo histórico y cultural propuesto por Thompson, quien recordaba a Althusser que

las personas no sólo viven su propia experiencia bajo la forma de ideas, en el marco del pensamiento y de sus procedimientos... También viven su propia experiencia como sentimiento y elaboran sus sentimientos en las coordenadas de su cultura, en tanto que normas, obligaciones y reciprocidades familiares y de parentesco, valores o - mediante formas más elaboradas - como experiencias artísticas o creencias religiosas. ${ }^{7}$

El "lenguaje real", dice Williams, nunca es autónomo y está compuesto por las palabras y secuencias de éstas que determinados hombres y mujeres emplearon al significar sus vivencias colectivas. Esclarecer estos conceptos y las conexiones respectivas articulándolos a la vez con la experiencia de la Revolución industrial es el programa subyacente a Culture and Society que, en su tentativa, acompaña a The of the Making English Working Class (1963), la obra mayor de Thompson. Mientras el intelectual galés trató de aprehender los significados que permitieron racionalizar la transformación del modo de vida de millares de personas, el historiador oxoniense procuró reconstruir la experiencia histórica que convirtió a la

\footnotetext{
${ }^{4}$ Ibid., $18,21$.

${ }_{5}^{5}$ Cevasco, Para leer a Raymond Williams, 179, 184; Raymond Williams, La larga revolución (Buenos Aires: Nueva Visión, 2003), 58; Williams, Palabras clave, 20; Gareth Stedman Jones, Lenguajes de clase. Estudios sobre la bistoria de la clase obrera inglesa (Madrid: Siglo Veintiuno, 1989), 21. Se citan los dos últimos.

${ }^{6}$ Williams, La larga revolución, 70; Hugues Portelli, Gramsci y el bloque bistórico, 1973, 6a ed. (México, Siglo Veintiuno: 1979), 18.

${ }^{7}$ E.P. Thompson, Miseria de la teoría (Barcelona: Crítica, 1981), 263. Énfasis propio.
} 
muchedumbre del siglo XVIII en una clase disciplinada en el primer tercio de la centuria siguiente rompiendo, en sus palabras, "con cierta ortodoxia 'marxista'... que creía que la clase obrera era una creación más o menos espontánea de las nuevas fuerzas productivas y relaciones de producción". 8

De ninguna forma el lenguaje pierde para Williams su referencialidad (material e histórica), las prácticas concretas a las que alude. En el caso específico de los vocablos industria, clase, cultura, arte y democracia, el referente histórico es el corte epocal que potenció como ninguno las capacidades productivas de la sociedad humana y, al mismo tiempo, marcó los límites de la civilización según entrevió el primer socialismo. No obstante, este proceso resulta incomprensible sin los conceptos que, vinculados entre sí, lo significan. Y esto vale tanto para los participantes directos de las transformaciones en el mundo del trabajo - la clase obrera estudiada por Thompson- como para los pensadores quienes intentaron captar las grandes transformaciones de la sociedad industrial, la "estructura de sentimiento" objeto de Culture and Society. Preguntarse por un orden de prelación carece de sentido, pues uno y otro están implicados recíprocamente, dado que "la conciencia es parte de la realidad y la realidad, parte de la conciencia, en el proceso general de nuestra organización viviente". Como tampoco tiene pertinencia afirmar que existe una base económica la cual determina a una superestructura jurídica e ideológica (donde algunos marxistas sitúan al lenguaje), porque esta división simplemente no es tal. Williams y Thompson combatieron esta postura que reducía la complejidad social al punto de despojarla de sus atributos, por lo que quedaron a resguardo de la objeción de White a una eventual historia intelectual marxista:

Si la historia intelectual toma como objeto especial las ideas, mentalités, los sistemas de pensamiento, los sistemas de valores e ideales de las sociedades particulares del pasado, [y] simplemente trata a éstos como datos que reflejan procesos aún más básicos... entonces la historia intelectual es supletoria en relación con la reconstrucción histórica de estos otros procesos, pues en este caso sólo puede duplicar los relatos proporcionados por los especialistas de estos otros campos de estudio... ${ }^{10}$

Pero rechazar que las ideas sean un simple "reflejo" de la base económica no supone negar el vínculo entre los distintos órdenes de lo real, lo cual complica en lugar de simplificar el análisis de las representaciones lingüísticas, ideológicas o de otra índole. Por el contrario, es más sencillo autonomizar la esfera de las ideas, dejándolas al margen de la totalidad social, preocupación cardinal del materialismo cultural.

Indicados estos "parecidos de familia", podemos volver a las discretas sugerencias que brinda Williams a los interesados en adentrarse en la historia de las "palabras clave”. Clave advierte - en dos sentidos: porque son "significativas y vinculantes en ciertas actividades así como en su interpretación"; porque son "significativas e indicativas en ciertas formas de pensamiento”. Prácticas y reflexivas simultáneamente, en la medida en que están imbricadas con la realidad, a la que constituyen y quien las dota de entidad; también, porque no existe una separación tajante entre la cultura popular y la alta cultura, ambas integradas en lo que llama "modo de vida". ${ }^{11}$

Ni siquiera el arte escapa a esta naturaleza terrena, a formas comunicativas establecidas socialmente y acotadas por la historia, no obstante que la civilización burguesa lo confinó a una

\footnotetext{
${ }^{8}$ E.P. Thompson, La formación de la clase obrera en Inglaterra, vol. 1, 1977, $2^{\text {a }}$. ed. prólogo de Josep Fontana (Barcelona: Crítica, 1989), 19.

${ }_{9}$ Williams, La larga revolución, 36.

${ }^{10}$ Hayden White, El contenido de la forma. Narrativa, discurso y representación histórica (Barcelona, Paidós: 1992), 216.

11 Williams, Palabras clave, 19; Williams, La larga revolución, 56.
} 
zona de experiencia particular -llámese emoción, belleza, fantasía, imaginación o inconscientee impenetrable, si bien en la práctica nunca se limitó a ésta,

ya que en realidad se extiende desde las actividades cotidianas más corrientes hasta crisis e intensidades excepcionales y utiliza una gama de medios, desde las palabras de la calle y las historias populares comunes hasta extraños sistemas e imágenes que, sin embargo, pudo convertir en propiedad de todos. ${ }^{12}$

Habitualmente el lenguaje ordinario registra los cambios en el mundo material antes de que los textos escritos dejen constancia de ellos. Por eruditos que sean, los diccionarios suelen llevar ese retraso con respecto del lenguaje oral, lo cual vale especialmente para los términos de uso corriente. De otro lado, cuando se trata de conceptos intelectualmente más elaborados, la fuente de autoridad principal es el lenguaje escrito. Asimismo, la perspectiva que ofrecen estos grandes compendios de la lengua tiene una impronta etimológica y filológica, soslayando la conexión e interacción de los vocablos. Y, en ocasiones, "especialmente en ciertos términos sociales y políticos sensibles, los supuestos de la opinión ortodoxa... se dejan ver o no están muy por debajo de la superficie". En rigor, al trabajar con estos materiales "implica tener por momentos de lo que puede llamarse la ideología de los compiladores, y me parece que esto, sencillamente, hay que aceptarlo y admitirlo..."13

Las limitaciones no son solamente esas; otras más tienen que ver con que palabras importantes han transitado por varias lenguas y, a falta de estudios equivalentes para distintos países, es casi imposible reconstruir la secuencia completa de las variaciones de su significado. No por ello deja de ser fascinante observar los cambios que pudieron registrar los diccionarios: si de suyo los significados primigenios son dignos de atención, "lo más interesante a menudo es su variación ulterior". Ahora bien, estas mutaciones no son meramente inerciales, ocurren porque los vocablos y su significado están insertos en relaciones reales, a menudo conflictivas, las cuales están en movimiento y sujetos a alteraciones en la medida en que operan dentro de estructuras más amplias y en sistemas sociales específicos formando parte de "los procesos de cambio social e histórico". Esto no quiere decir que la lengua sea un simple reflejo de estos; antes bien, Keywords se propuso mostrar "que algunos procesos sociales e históricos se producen dentro de ella, de una manera que indica hasta qué punto son realmente integrales los problemas del significado y las relaciones". Constantemente surgen nuevas relaciones o cambia la forma de enfocar las ya existentes, de manera tal que "los sentidos anteriores y posteriores coexisten o se convierten en verdaderas alternativas en donde se debaten los problemas de la creencia y de la filiación contemporáneas". ${ }^{14}$

\section{EL PRIMER “RACIMO” DE PALABRAS CLAVE}

Industria, arte, cultura, clase y democracia -dijimos- constituyeron el bloque inicial sobre el que comenzó a trabajar Williams, para extenderlo después a otras palabras. La característica esencial de esta primera selección es que sus significados son conexos y todos se modifican sustancialmente en el siglo XVIII, cuando ocurre la Revolución industrial, expresión tomada por cierto de los autores franceses que hicieron la obligada analogía con la revolución de 1789. Industria, arte y cultura se convierten en sustantivos, dejan de ser un atributo humano para transformarse en cosas, en instituciones con vida propia. Clase, en su acepción social, también proviene de ese tiempo señalando en principio la división de la sociedad en clases

12 Williams, La larga revolución, 50.

13 Williams, Palabras clave, 22.

${ }^{14}$ Ibid., 24, 25, 26. Énfasis propio. 
inferiores, medias y superiores, volviéndose más específico el término en las primeras décadas del siglo XIX. La palabra democracia, empleada en la Grecia antigua, irrumpió en el vocabulario político gracias a las revoluciones norteamericana y francesa, aunque con la carga negativa de su asociación con el jacobinismo y el gobierno de las clases bajas. ${ }^{15}$

Veamos con detenimiento estos cambios y sus implicaciones para darnos cuenta de la profundidad de su metamorfosis. Comencemos con la palabra latina industria. El vocablo aparece en inglés en el siglo XV y es sinónimo de "diligencia", lo que lo opone a la holgazanería y la torpeza. En el siglo XVI la palabra industrial sirvió para distinguir los frutos cultivados o industriales de los naturales. Apuntamos ya que en el siglo XVIII refiere a una institución productiva, significado que quedará plasmado en La riqueza de las naciones (1776), de Adam Smith. Para entonces, el sustantivo de alguna manera denota la escisión que en el mundo fabril se operó entre el obrero y la máquina, la separación de éste de los medios de producción y de los beneficios del trabajo, razón por la cual conectará con el concepto de alienación en su acepción marxista, esto es, cuando "el trabajador pierde a la vez el producto de su labor y el sentido de su propia actividad productiva, a consecuencia de la expropiación de ambos por el capital". ${ }^{16}$

Arte, del latín artem, está identificado en origen con la habilidad o destreza para hacer algo, remontándose su uso en inglés al siglo XIII. Mientras la industria implicaba una disposición, en consecuencia una inclinación moral del individuo que lo hacía optar por la diligencia y desdeñar la holgazanería, buscar hacer algo útil, el arte refería a una capacidad, por tanto a una virtud que se potenciaba con el trabajo, la disciplina, el estudio y los buenos hábitos. De hecho, eran prácticamente equivalentes el artesano y el artista todavía en el siglo XVI. Es hacia finales del siglo XVIII cuando se asocia a éste con la creación, la imaginación, la inteligencia e incluso con la espontaneidad, añadiéndosele posteriormente el ingrediente de la sensibilidad, en tanto que el artesano se identifica con el trabajo manual calificado y las artes mecánicas; sus objetos con la repetición, la producción en serie y la monotonía. La degradación del trabajo artesanal en la escala de la virtud fue uno de los motores del movimiento obrero francés de la primera mitad del siglo XIX y de la utopía estética de William Morris de finales de siglo. Para el genio de las artes decorativas, el arte tal como existía en la sociedad capitalista debería de desaparecer para resurgir en el socialismo donde la brecha entre las bellas artes y las artesanías, producto de la separación entre las elites ilustradas y las masas ignorantes, quedaría salvada. ${ }^{17}$

Cultura, de origen latino, liga con los verbos cultivar, habitar, proteger y honrar (con veneración). Cuando la palabra pasó al inglés en el siglo XV, el significado primordial estaba en la labranza, es decir, la atención al crecimiento natural. Un siglo después el contenido semántico se desplazó al desarrollo humano, perdurando esta acepción hasta principios del siglo XIX. Herder cuestionó la hipotética superioridad de la cultura europea -tan pretenciosa que se asume "universal"- y su imposición en el resto del planeta, a la vez que hizo una innovación capital al hablar de culturas en plural, llamando la atención sobre "las culturas específicas y variables de diferentes naciones y periodos, pero también las culturas específicas y variables de los grupos sociales y económicos dentro de una misma nación”. El romanticismo "desarrolló ampliamente este sentido como una alternativa a la "civilización" ortodoxa y dominante". ${ }^{18}$ Es así que Rousseau quiso convertir a la sociedad en una comunidad ética donde se tratara justa y respetuosamente a los sirvientes y a los trabajadores del campo, se preservara la naturaleza y consumieran mesuradamente sus recursos como los productos del trabajo. Y

15 Williams, Cultura y sociedad, 14-15. En 1794 se registra su uso en Francia. Hannah Arendt, Sobre la revolución (Madrid: Alianza, 2004), 159.

16 Williams, Palabras clave, 184, 35.

17 Ibid., 40-41; William H. Sewell, Jr., Trabajo y revolución en Francia. El lenguaje del movimiento obrero del antiguo régimen hasta 1848 (Barcelona: Taurus, 1992), 45; E.P. Thompson, William Morris. De romántico a revolucionario (Velencia: Edicions Alfons El Magnànim, 1988), 597 y ss.

18 Williams, Palabras clave, 90. Énfasis propio. 
Fourier diseñó un programa social para trascender esa calamidad que era la civilización conduciendo racional y productivamente las pasiones humanas, liberando sus pulsiones. La asociación ocuparía entonces el lugar de "la competencia individual, insolidaria, complicadora y arbitraria..." 19

La crisis de la hegemonía cultural de la gentry y las manifestaciones plebeyas de descontento, admirablemente tratadas por Thompson, corrieron simultáneamente a la conversión de la palabra cultura en sustantivo independiente que plasma la separación de la "alta cultura" de la "cultura popular". El paralelo con lo ocurrido con el arte es evidente, cuando relegó a la artesanía a un estrato inferior. La sensibilidad y la inteligencia, de creadores y espectadores, se convirtió en un asunto de pocos, aunque la novela democratizó como ninguna la cultura en el siglo XIX al extenderse la alfabetización a las clases medias y trabajadoras, además de desarrollarse el mercado editorial. ${ }^{20}$

Del latín classis, donde clasificaba a los romanos de acuerdo con los bienes que poseían, clase entró al inglés hacia finales del siglo XVI. Su acepción social moderna, que divide a la sociedad de acuerdo con su capacidad económica, corresponde al siglo XVIII, periodo en el cual surgen un conjunto de "singulares colectivos" (nación, historia, revolución, libertad, etcétera), como los llamó Koselleck, que disuelven la diversidad en una forma general. ${ }^{21}$ Fue entonces que comenzó a preocupar a algunas inteligencias agudas el conflicto entre las clases, de "masas que recíprocamente se enfrentan en el mundo" - decía Goethe -, en una constante discordia que Michelet intentaría vanamente solucionar. Esto, pensaba el conde de SaintSimon, era atribuible a las clases ociosas, improductivas o privilegiadas, razón por la cual los productores de "cosas útiles" eran quienes debían dirigir a la sociedad. ${ }^{22}$

El colectivo singular clase - en su vertiente de clase trabajadora - se sustanció en el movimiento obrero moderno el cual, efectivamente, subsumió la diversidad de oficios particulares y de trabajos concretos en un sustantivo y en la noción de trabajo abstracto. Incorporó también una organización (incluso partidaria), una épica histórica y una simbología que reforzaron la identidad que trascendía las fronteras nacionales y el color de la piel. Para continuar con Koselleck, el socialismo fue su "horizonte de expectativa" 23 en el tránsito al siglo XX. La imagen más poderosa desde 1890 continúa siendo el día del trabajo que,

de hecho, es una fiesta más universal que cualquier otra excepto el 25 de diciembre y el 1 de
enero, y ha dejado muy atrás a sus rivales religiosas. Pero surgió de la base. Le dieron forma
los propios obreros anónimos que, por medio de ella, se reconocieron a sí mismos como una sola
clase, a pesar de las barreras del oficio, de la lengua, incluso de la nacionalidad, cuando
decidieron que una vez al año se abstendrían deliberadamente de trabajar: harían caso omiso
de la obligación moral, política y económica de trabajar. ${ }^{24}$

A diferencia de las otras palabras, Democracia proviene del griego y, como todos sabemos, significa "gobierno o poder del pueblo". No había mayor problema mientras fuera

\footnotetext{
19 Jean-Jacques Rousseau, Julia, o la nueva Eloísa, prólogo y traducción de Pilar Ruiz Ortega (Madrid: Akal, 2007). 498 y ss.; Charles Fourier, El nuevo mundo industrial y societario, prólogo de Michel Butor (México: FCE, 1989), 52.

${ }^{20}$ E.P. Thompson, Costumbres en común (Barcelona: Crítica, 1995), 49 y ss.; Williams, Cultura y sociedad, 43 y ss.

21 Williams, Palabras clave, 62 y ss.; Reinhart Koselleck, historia/Historia, traducción e introducción de Antonio Gómez Ramos (Madrid: Trotta, 2004), 38.

22 Johann Wolfgang von Goethe, Las afinidades electivas, edición, traducción e introducción de Manuel José González y Marisa Barreno (Madrid: Cátedra, 2000), 110; Jules Michelet, El pueblo (México: FCE, 2005), 33 y ss.; Ghita Ionescu (ed.), Elpensamiento político de Saint-Simon (México: FCE, 1983), 118.

${ }^{23}$ Reinhart Koselleck, Futuro pasado. Para una semántica de los tiempos históricos (Barcelona: Paidós, 1993), 83.

${ }^{24}$ Eric J. Hobsbawm, Gente poco corriente. Resistencia, rebelión y jazz (Barcelona: Crítica, 1999), 147. Énfasis propio.
} 
claro qué era el gobierno y quién era el pueblo. Con la Revolución francesa - apunta Arendt"por primera vez el vocablo [pueblo] abarcó no sólo a quienes no participaban en el gobierno, es decir, no sólo a los ciudadanos, sino al pueblo bajo". De hecho, como la acepción corriente identificaba a la democracia con el gobierno de la gente común,

la palabra fue hasta el siglo XIX un término fuertemente desfavorable, y recién entre fines de este siglo y principios del siglo XX una mayoria de partidos y corrientes políticas se unieron en una declaración de fe en la democracia. Éste - dice Williams - es el hecho bistórico más sorprendente.

Como también lo es que actualmente se asimile la democracia al liberalismo pues, en rigor - señala Bobbio - "un Estado liberal no es por fuerza democrático: más aún, históricamente se realiza en sociedades en las cuales la participación en el gobierno está muy restringida, limitada a las clases pudientes". En este sentido, el relato de la formación de la clase obrera inglesa, realizado por Thompson, comienza justamente cuando artesanos de distintos oficios se dan cuenta de que, a pesar de ser la mayoría de la sociedad, carecían de la representación política monopolizada por los propietarios: comandados por un zapatero, esos “innumerables miembros” formarían en 1792 la Sociedad de Correspondencia de Londres. De igual forma - señala Stedman Jones -, la fuerza del movimiento cartista "residió en su identificación del poder como fuente de la opresión social y en su capacidad de concentrar en un objetivo común el descontento de las clases obreras sin representación". ${ }^{25}$

\section{LAS PALABRAS CLAVE DE HOY}

Sería difícil señalar cuáles son las palabras clave de la época actual y, de igual forma, escoger unas pocas que pudieran esbozar la estructura de sentimiento de la posmodernidad, o lógica cultural del capitalismo tardío - como la nombra Jameson - la cual domina el universo de nuestras representaciones. ${ }^{26}$ ¿Capitalismo, globalización, democracia, violencia, alienación, ecología, individuo, ciencia, comunidad, crisis, masas, trabajo, imagen, delincuencia, riqueza, desempleo?

A riesgo de hacer una selección arbitraria, o más bien con la certeza de que será así, tomaremos tres que pertenecen al ámbito social (capitalismo, violencia y desempleo) y son sin duda apropiadas, aunque insuficientes, para adentrarnos en el tiempo presente que parece cerrar la etapa histórica iniciada con la Revolución industrial, la cual autores como Lyotard han llamado "sociedad del conocimiento o sociedad posindustrial". ${ }^{27}$

La palabra capitalismo apareció en inglés a principios del siglo XIX y, poco después, se incorporó al francés y al alemán. Los usos divergieron por lo general en considerarlo exclusivamente como un sistema económico o, a la vez que eso, como una formación histórica. De acuerdo con la primera acepción - nos recuerda Dobb -

se identifica con el sistema de iniciativa individual absolutamente libre: un sistema en que las relaciones económicas y sociales se reglan por contrato; en que los hombres se comportan como

\footnotetext{
25 Arendt, Sobre la revolución, 99; Williams, Palabras clave, 95; Norberto Bobbio, Liberalismo y democracia (México: FCE, 1989), 7; Thompson, La formación de la clase obrera en Inglaterra, vol. 1, 6 y ss.; Stedman Jones, Lenguajes de clase, 157.

${ }^{26}$ Fredric Jameson, El giro cultural. Escritos seleccionados sobre el posmodernismo 1983-1998, prólogo de Perry Anderson (Buenos Aires: Manantial, 1999), 57.

27 Perry Anderson, Los orígenes de la posmodernidad (Barcelona: Anagrama, 2000), 38.
} 
agentes libres en la búsqueda de su sustento y en que no bay compulsiones ni restricciones legales.

En el sentido de formación histórica, Marx lo caracterizó como un "modo de producción" fundamentado en la propiedad privada del capital y la explotación del trabajo; mientras Sombart y Weber lo vieron como la encarnación del "espíritu burgués”, una síntesis venturosa de aventura, cálculo y racionalidad. Identificado en principio con la libre competencia, a la vuelta del siglo Xx el capitalismo se manifestaba más bien bajo la forma de monopolios, tendencia que se profundizó con la concentración de capital que exigía la industria pesada de la segunda Revolución industrial (carbón, hierro; hidrocarburos, más adelante). En la tercera, pasaría a las industrias flexibles de las altas tecnologías (nanotecnología, cibernética, biotecnología). Actualmente, incluso, se separó de su geografía productiva, radicándose en el intangible mundo financiero. ${ }^{28}$

Violencia proviene del latín violentia, que significaba "vehemencia", "impetuosidad". Adoptada por el inglés, desde finales del siglo XIII denotó "fuerza física". Contra las autocracias, los revolucionarios del siglo XIX consideraron legítimo recurrir a ella, pero con la expansión de los sistemas democráticos la "violencia política" generó rechazo dentro de la opinión pública. En su sentido contemporáneo, para deslindar este empleo de la fuerza de acuerdo con quienes lo realizan, habitualmente se habla de violencia cuando se trata de entidades distintas del Estado - el que posee el monopolio legítimo de su uso, de acuerdo con Weber- y simplemente de fuerza, si éste es quien la emplea. De cualquier manera, para sus críticos, como la principal fuente de violencia es el poder, no deja de tratarse del "derecho a ejercer la violencia". ${ }^{29}$ Sin embargo, tanto la multiplicación de las fuentes de la violencia en la época actual - la guerra en todas sus formas, el despojo de comunidades enteras, la relocalización de las empresas dejando sin trabajo a miles de personas, la discriminación como de poderes ya no necesariamente estatales - pensemos en las organizaciones criminales o en los grupos paramilitares -, pero no por eso enteramente desligadas del Estado, introducen nuevas dificultades para su conceptualización.

El término desocupación designó desde el siglo XVI en Inglaterra a cosas que no se les daba ningún uso y, en la centuria siguiente, se extendió a personas vagabundas y ociosas. La economía política clásica asimiló el trabajo asalariado al empleo y, en su crítica de ésta, Marx consideró que la economía capitalista creaba un "ejército industrial de reserva", esto es, de trabajadores desocupados y disponibles, para pagar salarios bajos y abaratar los costes de producción. Todavía a finales del siglo xx mantenía vigencia la asociación del trabajo con el empleo, pues, quienes hablaban del "fin del trabajo", aludían al mismo tiempo al desempleo provocado por el desplazamiento de la mano de obra por las máquinas, característica de una nueva civilización “en la que sólo una pequeña parte de la población encontrará funciones". 30

Por tanto, el desempleo es uno de los problemas medulares de la sociedad contemporánea donde un amplio segmento de la fuerza laboral se alterna entre el trabajo precario y el paro, por lo que algunos hablan de la emergencia de una "clase trabajadora informal" la cual crece aceleradamente en las grandes concentraciones urbanas del planeta. ${ }^{31}$ Este fenómeno, aunado a la declinación de la clase obrera industrial y del campesinado,

${ }^{28}$ Maurice Dobb, Estudios sobre el desarrollo del capitalismo, 1971, 9ª ed. (México: Siglo Veintiuno, 1977), $17-$ 18; Jameson, El giro cultural, 188. Se cita el primero.

29 Williams, Palabras clave, 324-325; Bolívar Echeverría, Valor de uso y utopía (México: Siglo Veintiuno, 1998), 95; Étienne Balibar, Violencias, identidades y civilidad. Para una cultura politica global (Barcelona: Gedisa, 2005), 210.

30 Williams, Palabras clave, 101; Fernando Díez, El trabajo transfigurado. Los discursos del trabajo en la primera mitad de siglo XIX (Valencia: PUV, 2005), 25; Jeremy Rifkin, El fin del trabajo (México: Paidós, 1994), 33;

Viviane Forrester, El horror económico (México: FCE, 1997), 35. Se cita éste.

31 Mike Davis, Planeta de ciudades miseria (Madrid: Foca, 2007), 237. 
constituyen dos de las transformaciones más dramáticas de los últimos cincuenta años, puntos de inflexión dentro del proceso histórico global.

Si bien los fenómenos enunciados por estos tres vocablos vienen de antaño, lo cierto es que ahora se presentan de manera más cruda y con mayor recurrencia que en el pasado; la tecnología los potenció a una magnitud sin precedente aunque, al mismo tiempo, los hemos naturalizado a tal grado que la violencia no provoca ya horror, aunque ocasionalmente el desempleo suscita la indignación moral experimentada por los modernos. No obstante las mutaciones sufridas por el capitalismo en los últimos trescientos años, y el evidente declive de la clase obrera fabril, el sujeto social que de acuerdo con el marxismo sería quien lo enterraría, nadie duda que estemos todavía dentro de aquél, e incluso que vivimos dentro de un "capitalismo salvaje" o desregulado, que depreda tanto los derechos ganados históricamente por el trabajo como el medio ambiente, coloniza los últimos reductos que le faltaban -la naturaleza y el inconsciente- y no le cuesta ningún esfuerzo avenirse con la delincuencia, como muestra la asombrosa expansión del crimen organizado durante la era neoliberal, servirse de formas actualizadas de trabajo coactivo o explotar el trabajo infantil. Es más - señala Eagleton el capitalismo actual "requiere un ser humano que todavía no ha existido: un ser humano que sea prudentemente sobrio en la oficina y salvajemente anárquico en el centro comercial". ${ }^{32}$

\footnotetext{
32 Terry Eagleton, Después de la teoría (Barcelona: Debate, 2005), 40.
} 